\title{
The susceptibility of pregnant women during viral pandemics - a mini-review
}

\author{
Astrit M. Gashi, Jakup Ismajli, Arjanit Sherifi, Gent Sopa, Dardan Ismajli \\ Department of Obstetrics and Gynecology, University Clinical Center of Kosovo, \\ University of Pristine, Kosovo
}

\begin{abstract}
The immune system is a system that consists of the reaction of the organism to the aggression of invading pathogens. The immune system is composed of: the innate immune system or nonspecific immunity, and the acquired immune system or specific immunity. During pregnancy, the maternal immune system changes constantly. The objective of this review is to evaluate the results from studies made in the field of reproductive immunology about the susceptibility of pregnant women to infectious diseases. Most studies show that pregnant women may be at a higher risk and more susceptible to infectious diseases. This is due to the continuous immune system modulating that occurs during pregnancy. This immunity modulated during normal pregnancy consists of decreased the acquired immune system or specific immunity (B-cells are absent, while T lymphocytes constitute about $3-10 \%$ of the decidual immune cells).

We conclude that pregnant women may be at a higher risk and more susceptible to infectious diseases, including COVID-19. Therefore, we recommend special care and correct observance of measures such as social distancing, frequent hand washing, the use of masks, and all other measures that are given to the general population during viral pandemics, while pregnant women who become ill with COVID-19 should be treated aggressively. Furthermore, concrete plans must be developed (with more specific measures) for this higher-risk population, while ensuring that women receive the necessary care.
\end{abstract}

Keywords: pregnancy, immune system, susceptibility, COVID-19

\section{INTRODUCTION}

In general, the immune system consists of the reaction of the organism to the aggression of invading pathogens. The immune system is divided into two categories: 1) the innate immune system or nonspecific immunity, which characterized by rapid response to aggression, regardless of the previous stimulus. Innate immunity is the first line of defense and includes physical, chemical and biological barriers, cellular components, as well as soluble molecules, and 2) the acquired immune system or specific immunity, which characterized by the response against a previously recognized specific microorganism or antigen. The acquired immune system is the second line of immune defense to eliminate the infection and consists of $\mathrm{T}$ lymphocytes and B lymphocytes. Initially, pathogenic agents are recognized by the innate immune system, and then the acquired immune system is activated. Each of these two immune systems, in the fight against various pathogens (infections), complements each other. The characteristic of the innate immune system is that it uses fast and nonspecific methods to distinguish pathogenic agents. But there are also cases when pathogen agents evolve much faster than the reaction of the innate immune system. We have encapsulated viruses that are not recognized by the cells of the innate immune system, and to eradicate them it is necessary to activate the specific recognition or acquired immune system. Acquired immunity reacts through the production of lymphocytes or antibodies against specific antigens of pathogenic agents, eliminating the infection that has escaped the innate immune system. Pathogenic agents have developed several mechanisms to avoid innate and acquired immune systems. These mecha- 
nisms include the production of anti-inflammatory cytokines, reduction of major histocompatibility complex (MHC) class II molecules, and direct killing of specific host immune cells $(1,2)$. Being that during pregnancy, the women's immune system changes constantly, in terms of reducing the acquired immune system, this is due to the immunological tolerance to the fetus, which normally occurs during pregnancy. This reduction in the acquired immune system will make a pregnant woman more susceptible to various infections, especially viral ones $(3,4)$.

\section{THE MATERNAL IMMUNE SYSTEM}

Based on a lot of medical and evolutionary aspects, the immune system during pregnancy can be defined as a "sui generis" state and can activate all the means to protect the mother and the fetus. Therefore theoretically, we have the right to refer to pregnancy as a condition with the immunity of modulated, but not suppressed. Most studies around the immune system during a normal pregnancy show that some aspects of the acquired immunity are decreased during pregnancy, such as $\mathrm{T}$ cell and $\mathrm{B}$ cell frequencies and the ability of naive CD4+ T cells to produce T helper cell 1 (TH1) and TH2-type cytokines, while innate immune responses are exacerbated, such as natural killer (NK) cell, monocyte, and plasmacytoid dendritic cell (pDC) cytokine responses when stimulated with viral particles (5-10). Also, many factors are known that promote immune suppression during normal pregnancy (for example progesterone). This modulation of the immune system runs in terms of reducing the acquired immune system (inhibition of T lymphocytes), this is due to the immunological tolerance to the fetus, which normally occurs during pregnancy. Also, during pregnancy, several mechanisms inhibit the mother's T lymphocyte response. A specialized population of $\mathrm{T}$ lymphocytes, known as regulatory T cells (CD4, CD25), inhibits antigen-specific immune responses (11-14). Regulatory $\mathrm{T}$ cells inhibit the $\mathrm{T}$ lymphocyte response and realize it through direct contact with these cells, or by cytokines, such as Interleukin 10 (IL-10) and factor $\beta$ of transformation and maturation. Some studies have shown that high estrogen levels during pregnancy increase the proliferation of regulatory $\mathrm{T}$ cells $(15,16)$. There are other mechanisms as well to inhibit the mother's $\mathrm{T}$ lymphocyte responses, for example through enzyme Indoleamine -2, 3 - Dioxygenases, making the tryptophan disintegrates. Tryptophan is an amino acid necessary for the functioning of $\mathrm{T}$ lymphocytes $(17,18)$. Maternal $\mathrm{T}$ lymphocytes can also be inactivated through the interaction of the Fasligand (FasL) with the Apo-2L ligand, which triggers apoptosis depending on the tumor necrosis factor (TNF) (19).

\section{COPING WITH VIRAL PANDEMICS}

Viral pandemics occur when a new virus, to which the population has no immunity, spreads efficiently between humans and results in worldwide outbreaks of severe diseases. Pandemics occur infrequently but can be devastating in terms of the effects on morbidity and mortality, especially in a population with low immunity and pregnant women as one vulnerable population. It is known that the common cold is an acute infection of the respiratory tract caused by a variety of RNA viruses, including many rhinoviruses and several coronaviruses. The infection spreads from person to person through contact with infected secretions. Viruses parasitize respiratory epithelial cells, causing increased mucus production and tissue swelling, which then give clinical symptoms. It is generally known that due to previous outbreaks of the common cold, there have been more deaths and poorer outcomes among pregnant women compared with nonpregnant women (20-22). We still currently don't have data based on COVID-19 in pregnancy. Therefore, COVID-19 in pregnancy is being considered as an equation, with more unknowns. The immunity modulated during normal pregnancy consists of decreased the acquired immune system or specific immunity (B-cells are absent, while $\mathrm{T}$ lymphocytes constitute about $3-10 \%$ of the decidual immune cells). Therefore, pregnant women with a special population may be at a higher risk and more susceptible to or more severely affected by infectious diseases, especially during viral pandemics. It has been confirmed that systemic maternal viral infections can also affect pregnancy and cause various complications. These pregnancy complications may be caused by the direct effects of viruses on mothers. Current data show that in severe cases, COVID-19 infection is associated with a cytokine storm, which is characterized by increased plasma concentrations of interleukins 2 (IL-2), IL-7, IL-10, granulocyte colonystimulating factor, interferon- $\gamma$-inducible protein 10 , monocyte chemoattractant protein 1 , macrophage in- 
flammatory protein 1 alpha, and tumor necrosis factor $\alpha(\mathrm{TNF}-\alpha)$. This cytokine storm induced by SARS-CoV-2 may induce a more severe inflammatory state in these women (23). Therefore, pregnant women should have special care, especially during viral pandemics such as corona-virus disease (COVID-19).

\section{DISCUSSION}

The coronavirus disease was first found in December 2019 in Wuhan, in China. The virus that causes coronavirus disease 19 is called SARS-CoV-2. Coronaviruses are members of the Orthocoronavirinae subfamily and the Coronaviridae family. They are a group of related RNA viruses that cause diseases in birds and mammals. In humans, these viruses cause respiratory tract infections that can be lethal. The coronavirus disease has been rapidly spreading all over the world. Certain groups of the population have been detected that have a higher sensitivity to COVID-19, such as; the elders, newborns, especially, pregnant women may be more susceptible to COVID-19 since pregnant women, in general, are vulnerable to respiratory infection. Many viral epidemics and pandemics during pregnancy show how pregnant women suffer from unfavorable perinatal outcomes (fetal-maternal) in comparison with the general population and non-pregnant women (24). It is well known that a pregnant woman undergoes an immunological transformation, where the immune system is necessary to promote and support the pregnancy and growing fetus. In these conditions, pregnant women are considered to be in a special population group due to their specific susceptibility to some infectious diseases because of the "sui generis immunological' condition caused by pregnancy. Many studies have discussed viral pandemics in the general population, but limited attention has been given to the effects on pregnant women and their babies. Some studies have shown that pregnant women, in addition to being more susceptible to viral infections, are even at high risk for severe complications during viral pandemics, this is due to immunologic and physiologic alterations that occur during normal pregnancy. Physiological alterations that occur during pregnancy in the cardiovascular and respiratory systems, including increased heart rate, stroke volume, oxygen consumption, and decreased lung capacity (25), constitute some additional risk factors increased during viral pandemics. Of all the viral pandemics that have occurred, morbidity and mortality rates have been the highest among pregnant women compared to the general population. For example, mortality rates among pregnant women in the pandemics of 1918 and 1957 (influenza pandemics) were high, 27 percent in 1918, and 20 percent in 1957 $(26,27)$, and the most common complications were cardiopulmonary events (28). An analysis performed on the CDC for the H1N1 pandemic (2009), mortality rates among pregnant women were 21.6 percent (were 347 severely ill pregnant women, 75 died from 2009 H1N1, and 272 were admitted to an intensivecare unit and survived) (29). Ebola and Lassa viruses cause severe hemorrhagic fevers. Even in these epidemics, mortality among pregnant women was found to be higher than in the general population or nonpregnant women. In the 1976 epidemic, 46 percent of the 177 Ebola-infected women were pregnant and the overall mortality among pregnant women was $89 \%$ $(30,31)$. Three systematic reviews found that pregnant women have higher mortality rates associated with varicella virus infection, which is ten times more likely to be complicated by pneumonia during pregnancy (32-34). High mortality rates were also confirmed for rubeola $(35,36)$, and $1957 \mathrm{H} 5 \mathrm{~N} 1$ pandemics $(37,38)$. Pregnant women are also more susceptible and have higher mortality rates for SARS-CoV and MERS-CoV. It has been confirmed that viral infections during pregnancy can affect fetal development and maternal mortality and are therefore a major clinical problem worldwide; therefore public health institutions need to develop concrete plans for future viral pandemics, with specific measures for pregnant women.

\section{CONCLUSIONS}

Based on the previous viral pandemics, we confirm that pregnant women are more susceptible to respiratory pathogens, and consequently, they may be more susceptible to COVID-19 infection compared to the general population. While due to the characteristic immune responses during pregnancy and potential risks from the cytokine-storm by COVID-19 infection, pregnant women with COVID-19 may have severe morbidity and higher mortality rates.

It has been proven that immunological changes associated with pregnancy can increase the severity of some types of viral infections. For example, preg- 
nant women are more susceptible to rubella virus, varicella, H1N1 flu, influenza when compared to the general population, but the reason for the increase in susceptibility has not been well defined. Viral infections during pregnancy can have a negative impact on the mother and fetus and currently, we have not yet developed adequate tools to prevent infection and treatment of pregnant women during pandemics such as: influenza, Ebola, SARS-CoV, MERS-CoV, and COVID-19.

Based on the limited information available for coronavirus disease 2019 (COVID-19) in pregnancy, we confirm that pregnant women (as well as for other viral infections) may be at a higher risk and more sus- ceptible to COVID-19. We recommend special care and correct observance of measures such as social distancing, frequent hand washing, the use of masks, and all other measures that are given to the general population during viral pandemics, while pregnant women who become ill with COVID-19 should be treated aggressively.

Based on this data, pregnant women should be considered a population with a high-risk during viral pandemics, and concrete plans must be developed (with more specific measures) for this higher-risk population while ensuring that women receive the necessary care.

Conflict of interest: none declared Financial support: none declared

\section{REFERENCES}

1. McGuirk P, McCann C, Mills KH. Pathogen-specific T regulatory 1 cells induced in the respiratory tract by a bacterial molecule that stimulates interleukin 10 production by dendritic cells: a novel strategy for evasion of protective T helper type 1 responses by Bordetella pertussis. The Journal of Experimental Medicine. 2002 Jan 21;195(2):221-31.

2. Parker DC. T cell-dependent B cell activation. Annual Review of Immunology. $1993 \mathrm{Apr} ; 11(1): 331-60$.

3. Tafuri A, Alferink J, Möller P, Hämmerling GJ, Arnold B. T cell awareness of paternal alloantigens during pregnancy. Science. 1995 Oct 27;270(5236):630-3.

4. Jiang SP, Vacchio MS. Cutting edge: multiple mechanisms of peripheral T cell tolerance to the fetal "allograft". The Journal of Immunology. 1998 Apr 1;160(7):3086-90.

5. Romero R, Erez O, Maymon E, Chaemsaithong P, Xu Z, Pacora P, Chaiworapongsa T, Done B, Hassan SS, Tarca AL. The maternal plasma proteome changes as a function of gestational age in normal pregnancy: a longitudinal study. American Journal of Obstetrics and Gynecology. 2017 Jul 1;217(1):67-e1.

6. Pazos M, Sperling RS, Moran TM, Kraus TA. The influence of pregnancy on systemic immunity. Immunologic Research. 2012 Dec 1;54(1-3):254-61.

7. Kay AW, Fukuyama J, Aziz N, Dekker CL, Mackey S, Swan GE, Davis MM, Holmes S, Blish CA. Enhanced natural killer-cell and T-cell responses to influenza A virus during pregnancy. Proceedings of the National Academy of Sciences. 2014 Oct 7;111(40):14506-11.

8. Le Gars M, Kay AW, Bayless NL, Aziz N, Dekker CL, Swan GE, Davis MM, Blish CA. Increased proinflammatory responses of monocytes and plasmacytoid dendritic cells to influenza $A$ virus infection during pregnancy. The Journal of Infectious Diseases. 2016 Dec 1;214(11):1666-71.

9. Wicherek L, Basta P, Pitynski K, Marianowski P, Kijowski J, Wiatr J, Majka M. The Characterization of the Subpopulation of Suppressive B7H4+ Macrophages and the Subpopulation of CD25+ CD4+ and FOXP3+ Regulatory T-cells in Decidua during the Secretory Cycle Phase, Arias Stella Reaction, and Spontaneous Abortion-A Preliminary Report. American Journal of Reproductive Immunology. 2009 Apr; 61(4):303-12.

10. Aghaeepour N, Ganio EA, Mcilwain D, Tsai AS, Tingle M, Van Gassen S, Gaudilliere DK, Baca Q, McNeil L, Okada R, Ghaemi MS. An immune clock of human pregnancy. Science Immunology. 2017 Sep 1;2(15).

11. Sakaguchi S. Regulatory T cells: key controllers of immunologic self-tolerance. Cell. 2000 May 26;101(5):455-8.

12. Shevach EM. CD4+CD25+ suppressor T cells: more questions than answers. Nature Reviews Immunology. 2002 Jun;2(6):389-400.
13. Somerset DA, Zheng Y, Kilby MD, Sansom DM, Drayson MT. Normal human pregnancy is associated with an elevation in the immune suppressive CD25+CD4+ regulatory T-cell subset. Immunology. 2004 May;112(1):38-43.

14. Aluvihare VR, Kallikourdis M, Betz AG. Regulatory T cells mediate maternal tolerance to the fetus. Nature Immunology. 2004 Mar; 5(3):266-71.

15. Polanczyk MJ, Carson BD, Subramanian S, Afentoulis M, Vandenbark $\mathrm{AA}$, and Ziegler SF, Offner $\mathrm{H}$. Cutting edge: estrogen drives expansion of the CD4+ CD25+ regulatory T cell compartment. The Journal of Immunology. 2004 Aug 15;173(4):2227-30.

16. Zenclussen AC. Regulatory $T$ cells in pregnancy. Seminars in Immunopathology (Springer-Verlag.) 2006;28(1):31-39).

17. Munn DH, Shafizadeh E, Attwood JT, Bondarev I, Pashine A, Mellor AL. Inhibition of T cell proliferation by macrophage tryptophan catabolism. The Journal of Experimental Medicine. 1999 May 3;189(9):1363-72.

18. Suzuki S, Tone S, Takikawa O, Kubo T, Kohno I, Minatogawa Y. Expression of indoleamine 2, 3-dioxygenase and tryptophan 2, 3-dioxygenase in early concept. Biochemical Journal. $2001 \mathrm{Apr}$ 15;355(2):425-9.

19. Hammer A, Dohr G. Expression of Fas-ligand in first trimester and term human placental villi. Journal of Reproductive Immunology. 2000 Mar 1;46(2):83-90.

20. Kourtis AP, Read JS, Jamieson DJ. Pregnancy and infection. New England Journal of Medicine. 2014 Jun 5;370(23):2211-8.

21. Rasmussen SA, Jamieson DJ, Uyeki TM. Effects of influenza on pregnant women and infants. American Journal of Obstetrics and Gynecology. 2012 Sep 1;207(3):S3-8.

22. Hui DS. Epidemic and Emerging coronaviruses (severe acute respiratory syndrome and middle east respiratory syndrome). Clinics in chest medicine. 2017 Mar 1;38(1):71-86.

23. Huang C, Wang Y, Li X, Ren L, Zhao J, Hu Y, Zhang L, Fan G, Xu J, Gu X, Cheng Z. Clinical features of patients infected with 2019 novel coronavirus in Wuhan, China. The Lancet. 2020 Feb 15; 395(10223):497-506.

24. Gervasi MT, Romero R, Bracalente G, Chaiworapongsa T, Erez O, Dong Z, Hassan SS, Yeo L, Yoon BH, Mor G, Barzon L. Viral invasion of the amniotic cavity (VIAC) in the midtrimester of pregnancy. The Journal of Maternal-Fetal \& Neonatal Medicine. 2012 Oct 1;25(10):2002-13.

25. Goodnight WH, Soper DE. Pneumonia in pregnancy. Critical Care Medicine. 2005 Oct 1;33(10):S390-7.

26. Harris JW. Influenza occurring in pregnant women: a statistical study of thirteen hundred and fifty cases. Journal of the American Medical Association. 1919 Apr 5;72(14):978-80. 
27. Freeman DW, Barno A. Deaths from Asian influenza associated with pregnancy. American Journal of Obstetrics \& Gynecology. 1959 Dec 1;78(6):1172-5.

28. Neuzil KM, Reed GW, Mitchel EF, Simonsen L, Griffin MR. Impact of influenza on acute cardiopulmonary hospitalizations in pregnant women. American Journal of Epidemiology. 1998 Dec 1; 148(11):1094-102.

29. Centers for Disease Control and Prevention (CDC. Maternal and infant outcomes among severely ill pregnant and postpartum women with 2009 pandemic influenza A (H1N1)--United States, April 2009-August 2010. MMWR. Morbidity and mortality weekly report. 2011 Sep 9;60(35):1193.

30. Bwaka MA, Bonnet MJ, Calain P, Colebunders R, De Roo A, Guimard Y, Katwiki KR, Kibadi K, Kipasa MA, Kuvula KJ, Mapanda BB. Ebola hemorrhagic fever in Kikwit, Democratic Republic of the Congo: clinical observations in 103 patients. The Journal of infectious diseases. 1999 Feb 1;179(Supplement_1):S1-7.

31. Mupapa K, Mukundu W, Bwaka MA, Kipasa M, De Roo A, Kuvula K, Kibadi K, Massamba M, Ndaberey D, Colebunders R, MuyembeTamfum JJ. Ebola hemorrhagic fever and pregnancy. The Journal of infectious diseases. 1999 Feb 1;179(Supplement_1):S11-2.

32. Jamieson DJ, Theiler RN, Rasmussen SA. Emerging infections and pregnancy. Emerging infectious diseases. 2006 Nov;12(11):1638.
33. Haake DA, Zakowski PC, Haake DL, Bryson YJ. Early treatment with acyclovir for varicella pneumonia in otherwise healthy adults: retrospective controlled study and review. Reviews of infectious diseases. 1990 Sep 1;12(5):788-98.

34. Paryani SG, Arvin AM. Intrauterine infection with varicella-zoster virus after maternal varicella. New England Journal of Medicine. 1986 Jun 12;314(24):1542-6.

35. Atmar RL, Englund JA, Hammill H. Complications of measles during pregnancy. Clinical infectious diseases. 1992 Jan 1;14(1):217-26.

36. Christensen PE, Schmidt H, Bang HO, Andersen V, Jordal B, Jensen O. An epidemic of measles in southern Greenland, 1951; measles in virgin soil. II. The epidemic proper. Acta Medica Scandinavica. 1953;144(6):430.

37. Hardy JM, Azarowicz EN, Mannini A, Medearis Jr DN, Cooke RE. The effect of Asian influenza on the outcome of pregnancy, Baltimore, 1957-1958. American Journal of Public Health and the Nations Health. 1961 Aug;51(8):1182-8.

38. Freeman DW, Barno A. Deaths from Asian influenza associated with pregnancy. American Journal of Obstetrics \& Gynecology. 1959 Dec 1;78(6):1172-5. 